\title{
COVİD-19 pandemi sürecinde konaklama işletmelerinde tedarik zincirinde tedarikçi performansının değerlendirilmesi
}

\section{Assessment of supplier performance in the supply chain of hospitality enterprises during the COVID-19 pandemic process}

${ }^{1}$ Dr., İzmir, Türkiye,
serbulentkapici@yahoo.com

ORCID: 0000-0001-9462-9245

2 Dr. Öğr. Üyesi, Sinop Üniversitesi, Sinop, Türkiye, iguclu@sinop.edu.tr

ORCID: 0000-0002-9196-7844

${ }^{3}$ Dr. Öğr. Üyesi, Malatya Turgut Özal Üniversitesi, Malatya, Türkiye, emre.karakas@ozal.edu.tr

ORCID: 0000-0003-0123-7627

\section{Sorumlu Yazar/Corresponding Author:}

Dr. Serbülent Kapıcı,

İzmir, Türkiye,

serbulentkapici@yahoo.com

\section{Başvuru/Submitted: 22/05/2021}

$1^{\text {th }}$ Revizyon/Revised: $16 / 08 / 2021$

$2^{\text {nd }}$ Revizyon/Revised: 25/08/2021

Kabul/Accepted: 3/10/2021

Yayın/Online Published: 25/12/2021

Atıf/Citation: Kapıc1, S., \& Güçlü, İ., Karakaş, Y.E., COVID-19 pandemi sürecinde konaklama işletmelerinde tedarik zincirinde tedarikçi performansının değerlendirilmesi, bmij (2021) 9 (4): 12171237, doi: https://doi.org/10.15295/bmij.v9i4.1845

\author{
Serbülent Kapıc1 ${ }^{1}$ \\ İsmail Güçlü² \\ Yusuf Emre Karakaş3
}

Öz

İşletmeler değişen pazar koşulları ile birlikte yoğun rekabetin yaşandığı piyasalarda, tüketicilerin ihtiyaçlarını etkin ve hızlı bir şekilde karşılamak durumundadır. Bu da tedarik zincirindeki bütün fonksiyonların birbiri ile uyumlu bir şekilde çalışmalarını gerektirmektedir. İşletmelerin müşteri memnuniyetlerini en üst düzeye çıkarmak ve rekabet avantajını sürekli kılmak için tüm süreçlerin en iyi şekilde yönetilmesi büyük önem arz etmektedir. Firmaların mal ve hizmet alımı konusunda birlikte çalışacağı tedarikçilerin değerlendirilmesi önemli bir süreçtir. Bu husus, tedarikçiden beklenecek mal ve hizmetin kalitesi ve etkinliği bakımından büyük önem arz etmektedir. Müşteri memnuniyetinin önemli olduğu konaklama işletmelerinde tedarikçi performansının değerlendirilmesi, hizmetin kalitesine direkt etki edecek olması bakımından önemli bir problemdir. Bu çalışma, konaklama işletmelerinde faaliyet gösteren bir firmanın tedarikçi performans değerlendirmesi sürecini içermektedir. Bu çalışmadaki amaç, konaklama ve hizmet sektöründe performans değerlendirme ölçütlerini belirlemek, bu ölçütlere dayanarak potansiyel tedarikçileri belirlenen kriterler doğrultusunda değerlendirmek ve en uygun olanın tespit etmektir. Bu çalışmada çok kriterli karar verme yöntemlerinden biri olan Bulanık Analitik Hiyerarşi Prosesi (BAHP) ile COVID-19 sürecinde konaklama işletmelerinde tedarikçi secimi performansı değerlendirilmiştir. Sektörden satın alma uzmanlarından elde edilen bilgiler çözümlenerek nitel analize tabi tutulmuş ve bu araştırmanın ana kriterleri ile alt kriterleri oluşturulmuştur. Kriterlerin öncelik sırası ve ağırlıkları ikili karşılaştırma matrisleri kullanılarak bulunmuştur. Adana ilinde 5 yıldızlı bir konaklama işletmesinin pandemi sürecinde işletmenin gıda tedarikini sağlayan 3 tedarikçisi değerlendirilerek performansları ölçülmüştür.

Anahtar Kelimeler: Tedarik Zinciri Yönetimi, Tedarikçi Performansı, Konaklama İşletmeleri

Jel Kodları: M11, M31

\begin{abstract}
Businesses have to meet the needs of consumers effectively and quickly in markets where there is intense competition with changing market conditions. This requires that all functions in the supply chain work in harmony with each other. It is of great importance that all processes are managed in the best way to maximise the enterprises' customer satisfaction and maintain their competitive advantage. It is critical to evaluate the suppliers that companies will work with to purchase goods and services. This issue is of great importance regarding the quality and efficiency of the goods and services to be expected from the supplier. Evaluating supplier performance in hospitality businesses where customer satisfaction is essential is a critical problem, as it will directly affect the quality of the service. This study includes the supplier performance evaluation process of a company operating in hospitality businesses. The purpose of this study is to determine performance evaluation criteria in the hospitality and service sector, evaluate potential suppliers based on these criteria, and choose the most suitable one. This study assessed supplier selection performance in hospitality establishments during the COVID-19 process with the Fuzzy Analytical Hierarchy Process (AHP), one of the multicriteria decision-making methods. The information obtained from procurement experts from the sector was analyzed and subjected to qualitative analysis, and the main criteria and sub-criteria of this research were established. The priority order and weights of the bars were found using paired comparison matrices. During the pandemic process of the 5-star hospitality business in Adana, three food supply suppliers were evaluated, and their performances were measured.
\end{abstract}

Keywords: Supply Chain Management, Supplier Performance, Hospitality Businesses

Jel Codes: M11, M31 


\section{Extended Abstract}

\section{Assessment of supplier performance in the supply chain of hospitality enterprises during the COVID-19 pandemic process}

\section{Literature}

Companies must use performance evaluation and management systems determined according to their strategies and abilities to survive in the information age. Working in coordination and cooperation with suitable suppliers is essential for companies to achieve their goals. Supplier selection and performance evaluation of suppliers are strategically crucial in accommodation companies. The start of the COVID-19 process causes economic balances to deteriorate and many industries to be adversely affected. The sector most affected by this negativity is undoubtedly the tourism sector (Kivilcım, 2020, s. 21). Due to the prevalence of labour-intensive employment in the tourism sector, the high human-to-human interaction, the restriction of human movements and the prevention of travel during such an epidemic, the tourism sector has suffered a tremendous economic impact (Batman, Bilgiçli \& Yıldırgan, 2020).

One of the most important components in production and logistics planning activities is the supplier selection process for many businesses. Failure to select the right and effective supplier in industries can cause financial and operational damage to companies and cause many problems in the company's supply chains. Today, businesses can find many suppliers that they can work with. This situation makes the supplier evaluation and selection problem important for companies in today's world where competition is intense (Göktürk, Eryılmaz \& Yuluğkural, 2011). Choosing suitable suppliers significantly reduces the cost of purchasing materials. In addition, it increases corporate competitiveness, so many experts predict supplier selection is the most important activity for a purchasing department (Xia ve Wu, 2007, s. 494). A good supplier delivers the right product at the right price, in the right quality and specifications, in the correct quantity and at the right time. This will ensure that accommodation businesses do not interrupt the service process and supply products at optimum cost (Tellioğlu \& Etlioğlu, 2019, s. 147).

\section{Design and methods}

Buckley's Geometric Mean Technique was applied in Fuzzy AHP analysis in this study. Qualitative interviews were conducted with procurement experts from the industry, using semi-structured questions. The aim here is to determine the criteria that come to the fore in the performance evaluation of suppliers providing food supply in the accommodation sector during the pandemic process. The information obtained from procurement experts from the industry was analyzed and subjected to qualitative analysis, and the main criteria and sub-criteria of this research were established. During the interviews, it was emphasized that important changes were experienced in the supply market with the contraction in the sector during the pandemic process. In this process, it was stated that less stock was supplied with just-in-time shipments, and as a result, the management of safety stocks became critical. Furthermore, experts stated that before the pandemic, quality the price was necessary, while flexibility, delivery and hygiene criteria gained importance with this process.

The quantitative evaluation form was prepared using these criteria; It was filled in with an interview with the purchasing manager of a 5-star accommodation business in Adana and evaluated using the fuzzy AHP analysis method. In addition, during the pandemic process, three enterprise suppliers, which provide intensive food supply, were assessed.

\section{Findings and discussions}

It has been observed that Supplier A's payment approach, fulfilment of orders by quality requirements, packaging-shipping performance, product-time-quantity fulfilment, capacity-product diversity, product-business hygiene performance sub-criteria are high. In comparing the main criteria, it was determined that the delivery performance was first. On the other hand, supplier B's approach to payment, fulfilling orders following quality requirements, packaging-shipping performance, finding solutions to emergencies, being open to innovations, the course of the enterprise and its employees to pandemic rules, while the performance sub-criteria are observed to be high, the supplier profile performance is the priority in the comparison of the main criteria. It was determined that flexibility is in the second place. It is observed that Supplier C's payment approach, product quality, correct product and quantity delivery, product-time-quantity coverage, capacity-product diversity, and performance sub-criteria are equally high in the pandemic approach, while in the comparison of the main criteria, quality performance is the first. It was determined that the price is in the second place.

To compare the performance of suppliers with each other in terms of main performance criteria, we used the fuzzy AHP analysis method, which was explained in detail with the help of the fuzzy paired comparison matrix, and the weight vectors were obtained. As a result, the combined significance weights of the main performance criteria were accepted. As a result of comparing the suppliers with each other, it was observed that Supplier A in price performance, Supplier C in quality performance, Supplier A in delivery performance, Supplier B in flexibility performance, Supplier B in supplier profile performance and pandemic approach performance were observed to be equal.

\section{Conclusion and recommendation}

The supplier evaluation and selection process is vital and requires many criteria to be considered to manage the supply chain effectively. Businesses should analyze the suppliers they will work with according to these criteria and cooperate with the suppliers that meet the requirements they are looking. For companies, working with suitable suppliers by establishing business partnerships is a decision that directly affects business performance. The study in question was conducted for accommodation businesses. By applying this method, it can be done in different sectors using different evaluation criteria. In addition, decisionmakers can apply this method in the selection preferences of new suppliers. After the COVID-19 pandemic process, similar studies can be carried out to compare supplier performance evaluation. 


\section{Giriş}

Günümüz koşullarında işletmeler, mal ve hizmetlerin maliyetlerini ve verimliliklerini daha etkin kontrol etmek durumundadırlar. Bunu sağlayabilmek, sadece şirket içi süreçleri iyileştirmekle olmamakta aynı zamanda tedarik zincirinin parçası olan tedarikçilerle karşılıklı güvene dayalı bir işbirliğine gidilmesi ile mümkün olmaktadır. Tedarik zincirini oluşturan halkaların, zincir ortaklarının birbiri ile iletişimde olması, karşılıklı bilgi alışverişinde bulunarak alınan kararlardan haberdar olabilmesi çok daha etkin çalışılmasını sağlayacaktır. Tedarikçi seçimi ve değerlendirmesi satın alma boyutundaki en önemli konular arasında yer almaktadır çünkü malzeme ya da ürün alınan tedarikçinin yapısı son ürünün maliyet, ürün ve tasarım kalitesi ve üretilebilirliği gibi özelliklerine fazlasıyla etki etmektedir.

İşletmelerin tedarik zincirinin sağlıklı bir şekilde devamlılığının sağlanabilmesi için tedarikçi boyutunda ölçme ve değerlendirmenin sürekli yapılması ve sonrasında düzeltici önleyici faaliyetlerle aksaklıkların giderilmesi gerekmektedir. Şirketlerin, bilgi çağında yaşamlarını devam ettirebilmeleri için kendi strateji ve yeteneklerine göre belirlenen performans değerlendirme ve yönetim sistemlerini kullanmaları gerekmektedir. Doğru tedarikçilerle işbirliği ve koordineli olarak çalışmak, firmaların hedeflerine ulaşması için büyük önem arz etmektedir. Konaklama şirketlerinde tedarikçi seçimi ve tedarikçilerin performans değerlendirilmesi stratejik bir önem taşımaktadır.

\section{Literatür taramas1}

\section{Pandemi süreci ve işletmelere etkisi}

31 Aralık 2019'da Dünya Sağlık Örgütü (DSÖ), Çin'in Vuhan Şehrindeki nedeni bilinmeyen pnömoni vakaları hakkında bilgilendirilmesi ve 7 Ocak 2020 'de ise Çinli yetkililer tarafından yeni bir koronavirüs tespit edilmiştir (www.euro.who.int). Ülkemizde ilk COVID-19 vakası 11 Mart 2020'de saptanmıştır. Devam eden süreçte Dünyada olduğu gibi ülkemizde de vaka sayılarında artış görülmüştür (Sağlık Bakanlığ ${ }_{1}$ COVID-19, 2020, s. 9).

COVID-19 sürecinin başlaması ekonomik dengelerinin bozulmasına ve birçok sektörün olumsuz etkilenmesine neden olmaktadır. Bu olumsuzluktan en çok etkilenen sektör ise kuşkusuz turizm sektörüdür (Kıvılcım, 2020, s. 21). Turizm sektöründe emek-yoğun istihdamın yaygın olması, insandan insana etkileşimin çok yüksek olması ve böylesi bir salgın sürecinde insan hareketlerinin kısıtlanması ve seyahatlerin engellenmesi nedeniyle turizm sektörü ekonomik olarak büyük bir darbe almıstır (Batman, Bilgiçli ve Yıldırgan, 2020). Seyahat kısıtlamaları ile birlikte uçuşlar, otel rezervasyonları, festivaller iptal olmuştur. COVID-19 her şeyden önce insanların yaşamlarını etkileyen ve küresel bir ekonomik krizi tetikleyen insani bir kriz olarak ifade edilmektedir (Bahar ve Çelik İlal, 2020, s. 128).

COVID-19 bulaşma oranını düşürmeyi ve hastalığın yayılmasını engellemeyi amaçlayan sosyal uzaklaşma politikaları ve kapatma önlemleri (mağaza ve fabrika kapatmaları, karantina ve hareket kısıtlamaları) ile ekonomide keskin ve ani bir üretim düşüşüne neden olabilir. Toplu işten çıkarmalar nedeniyle gelirlerini kaybettiklerinde, harcamaları kısma veya ertelenebilir sosyal tüketimlerini (örneğin restoranlar, sinema salonları, barlar ve kulüpler, seyahat ve turizm) azaltma eğilimindedirler. Firmalar ayrıca COVID-19 ile ilişkili artan belirsizlik nedeniyle yatırımlarını erteleyebilmektedirler (Zheng ve Zhang, 2020, s. 1).

\section{Tedarik zinciri yönetimi}

Tedarik, işletmenin ihtiyacının belirlenmesi, bir tedarikçinin seçilmesi, fiyat ve ilgili diğer koşulların görüşülmesi ve teslimin sağlanmasının izlenmesi gibi fonksiyonlar topluluğunu kapsar (Acar ve Ateş, 2011, s. 18-19). Tedarik zinciri ise, hammadde ve parça tedariki, üretim ve montaj, depolama ve stok takibi, sipariş girişi ve sipariş yönetimi, tüm kanallar arasında dağıtım, müşteriye teslim dâhil olmak üzere hammaddeden müşteriye ürün teslimatında yer alan tüm faaliyetler ve bu faaliyetlerin tümünü izlemek için gerekli bilgi sistemleri olarak tanımlanır. Tedarik zinciri yönetimi, tüm bu aktiviteleri kusursuz bir süreçte koordine eder ve bütünleştirir. Bir kuruluş içindeki taraflar ve tedarikçiler, taşıyıcılar, üçüncü taraf şirketler ve bilgi sistemleri sağlayıcıları dâhil dış ortaklar da dâhil olmak üzere tüm paydaşları zincire bağlar (Habib, 2011, s. 6). Tedarik zinciri bir süreçtir. Hammadde kaynağının bulunmasından başlayarak, hammadde ve malzemenin alınması, üretim yerine getirilmesi, gerektiğinde depolanması, üretime alınarak mamul haline getirilmesi, pazarlanması ve doğrudan veya dolaylı olarak son kullanıcıya ulaştırılma sürecidir (Nebol, 2016, s. 4).

Tedarik zincirleri hızla değişen bir küresel ortamda faaliyet göstermektedir. Sadece toplumsal değişikliklerin değil, aynı zamanda tüketicilerin davranış biçimlerindeki değişikliklerin de lojistik üzerinde doğrudan etkisi bulunmaktadır. Dolayısıyla lojistik ortamın değişmekte olduğunu ve 
değişmeye devam edeceği söylenebilir. Bu değişim, şirketlerin tedarik zincirleri üzerinde doğrudan bir etkiye sahiptir (Lu ve De Bock, 2016, s. 53).

Tedarik Zinciri Yönetimi Ross'a (2000) göre tedarik zinciri yönetimi, firmaların hem kendi çapında hem de tedarik zinciri kanalında birlikte ittifak halinde bulunduğu ortaklarının sahip olduğu fonksiyonların ve kaynaklarının birleştirildiği, yüksek oranda rekabetçi, müşteri standardını artıran bir arz sistemi içerisinde, yaratıcı çözümler bulmak ve üst seviyede müşteri değeri yaratmak üzere kendisini ürün, hizmet ve bilginin pazara akışına odaklamış, sürekli gelişim gösteren bir yönetim felsefesidir. Mchirgui ve Sadraoui (2014), tedarik zinciri yönetimini, tedarikçi ve müşterileri, üretim ve hizmet sektöründeki organizasyonların istekleri ve esnekliklerini artırma yönündeki amaçlarına entegre etmesine yardımcı olan rekabetçi bir strateji olduğunu belirtmiştir.

\section{Tedarikçi performans değerlendirmesi}

Performans, bir işi yapan bir bireyin, bir grubun ya da bir teşebbüsün, o işle amaçlanan ve planlanan hedefe yönelik olarak, belirlenmiş bir zaman diliminde ya da birim zaman içerisinde, amaçlanan ve hedeflenen noktaya ne kadar varabildiğinin, başka bir ifadeyle neyi sağlayabildiğinin nicel ve nitel olarak belirleyen bir kavramdır (Akal, 2005, s. 17). Performans değerlendirme ise; insan kaynakları yönetiminin önemli işlevlerinden birisi olup, bireylerin örgütsel amaçlar doğrultusunda ve belirli bir dönem içerisinde ürettikleri sonuçların analiz edilmesi ve çeşitli alanlarda (ücret belirleme, terfi vb.) kullanilmasıdır (Akdemir, 2009, s. 487).

İşletmelerde tedarik yapılmadan önce ihtiyaçlar ile ihtiyaçların karşılanabilmesi için alınması planlanan ürün özellikleri tespit edilir. Sonra bu ürün ya da hizmeti sağlayacak tedarikçi araştırılır. Buna ilişkin teklifler toplanılır ve belirlenmiş kriterlere göre tedarikçi seçimi yapılır. Anlaşma yapılmasının ardından sipariş planı yapılır. İşletme tarafından düzenli bir şekilde tedarikçi performansı değerlendirmek maksadıyla takibi yapılır (Faris, Robinson ve Wind, 1967)

Tedarikçi performansını belirleyen çeşitli faktörler mevcuttur. Bu faktörlerin sayısı bazı yazarlara göre 13, bazılarına göre 18, bazılarına göre ise $60^{\prime}{ }_{1}$ bulmaktadır. Bu nedenle tedarikçi performansı değerlendirilmesi problemi çok kriterli bir problemdir. En iyi tedarikçi performansını belirlemede somut ve soyut faktörler arasında bir bağlantı kurmak gerekir (Ghodsypour ve O'Brien, 1998, Akt.Akman, G. Alkan, 2006). Performans değerlendirme, önceden belirlenen amaçlara ulaşmak için, tüm çalışanların çabalarının birleştirilmesi ve elde edilen sonuçların değerlendirilmesidir. Başka bir deyişle, önceden belirlenmiş standartlarla, çalışanların mevcut performanslarının karşılaştırılması ve değerlendirilmesi sürecidir. Böyle bir değerlendirme yapılırken bireylerin çok yönlü olarak ele alınması gerekir (Tunçer, 2013).

Birçok işletme için gerek üretim faaliyetlerinde gerekse lojistik planlama faaliyetlerindeki en önemli bileşenlerden birisi tedarikçi seçme sürecidir. İşletmelerde tedarikçi seçiminin doğru ve etkin bir şekilde yapılamaması, firmaları finansal ve operasyonel olarak zarara uğratmakla birlikte, firmanın içinde bulunduğu tedarik zincirlerinde de birçok problemin yaşanmasına neden olabilmektedir. Tedarikçi seçiminin doğru bir şekilde yapılabilmesi ise, satın alma maliyetlerinde azalma sağlarken, firmaların da rekabet gücünün artmasına imkân sağlamaktadır.

Tedarikçi seçim süreci, birçok şirket için üretim ve lojistik yönetiminin en önemli bileşenlerinden biridir. Yanlış bir tedarikçinin seçilmesi, şirketin finansal ve operasyonel durumunu olumsuz yönde etkiler. Doğru bir tedarikçi seçimi ise, satın alma maliyetlerini önemli ölçüde düşürür, pazardaki rekabet gücünü artırır ve son kullanıcı memnuniyetini artırır (Önüt vd., 2009). Günümüzde işletmeler çalışabilecekleri birçok tedarikçi bulabilmektedir. Bu durum da, rekabetin yoğun olduğu günümüz dünyasında, işletmeler açısından tedarikçi değerlendirme ve seçim problemini önemli bir hale getirmektedir (Göktürk, Eryılmaz ve Yuluğkural, 2011).

\section{Konaklama işletmelerinde tedarik süreci}

Konaklama işletmeleri; turizm işletmeleri içerisinde yer alan gelen misafirlerin gecelemelerinin yanında, yeme-içme ve eğlence ihtiyaçlarının da karşılandığı işletmelerdir Tabi bunlar içerisinde en önemli olanı otel işletmeleri olarak ifade edilebilir (Kozak vd., 2014, s. 49). Otel işletmelerinin sadece konaklama yapılan bir işletme olarak düşünülmemesi gerekmektedir. Aslında birincil işlevi olarak görülen konaklama hizmeti haricinde birçok farklı ihtiyaçlara yönelik hizmetler (yeme-içme, eğlence, spor, toplantı, sağlik vb.) sunabilen bir yaşam merkezi olarak da görülebilmektedir. Bu sebeple, otel işletmelerinin faaliyetlerini sürdürebilmeleri için farklı kalemlerde tedarik ihtiyaçları olmaktadır.

Manap Davras ve Karaatlı (2014), otel işletmelerinde tedarikçi seçiminde AHP yöntemini kullanmışalar ve kriterlerinin birbirleriyle karşılaştırılmaları sonucunda ise fiyat ve ürün kalitesi kriterlerinin diğer 
kriterlere göre daha önemli olduğunu tespit etmişlerdir. Önem sırasıyla diğer kriterler; güvenirlik, teslimat performansı, referans ve ödeme kolaylığının geldiği görülmüştür.

Sarığlan'ın (2018) çalışmasında, konaklama işletmelerinde tedarik edilen ürünlerin sınıflandırılması depolama özelliklerine ve saklama koşullarına göre yapılmıştır. Dayanaksız ürünler (sebze-meyve vb.), yarı dayanaklı ürünler (kuru baklagiller, dondurulmuş etler vb.), dayanaklı ürünler (deterjan, meşrubat $\mathrm{vb}$ ) ve duran varlıklar olarak ise demirbaşlardan (masa, sandalye vb.) oluşmaktadır. Tedarik zinciri genellikle örgütleri (paydaşlar ve ortaklar) birbirine bağlayan ve her örgütün girdilerini, çıktılarına bağlayan kritik bağlantılardan oluşan bir ağ yapısı olarak görülmektedir (Al-Aomar ve Hussain, 2017, s. 71). Tedarikçi seçimi, hizmet tedarik zincirinde müşteri memnuniyetini doğrudan etkileyen kritik bir stratejik karar sürecidir. Genel olarak tedarik zincir yönetimi stratejilerinin üretim yapan işletmeler için etkili olduğu düşünülse de, oteller ve sağlık kurumları gibi hizmet sektöründe yer alan işletmeler içinde büyük önem taşımaktadır. Ağırlama endüstrisinde, iyi yönetilebilen tedarikçi ilişkisi ile daha kaliteli hizmet ve daha düşük maliyetlerle rekabet avantajı sağlanabilmektedir (Önder ve Kabadayı, 2015).

Turizm sektöründe tedarik zinciri performansı hem finansal hem de finansal olmayan göstergeler ile ölçülebilmektedir. Yani, kâr, maliyet, pazar payı gibi performans göstergelerinin yanında bunların müşteri memnuniyeti, verimli iç süreçlerine, yenilik derecesine ve çalışan memnuniyetine olan etkileri de önemlidir (Tigu ve Călărețu, 2013, s. 106). Doğru tedarikçilerin seçilmesi, malzeme satın alma maliyetini önemli ölçüde azaltır ve kurumsal rekabet gücünü artırır, bu nedenle birçok uzman, tedarikçi seçiminin bir satın alma departmanı için en önemli faaliyet olduğu ön görüsündedirler (Xia ve Wu, 2007, s. 494). İyi bir tedarikçi doğru ürünü, doğru fiyata, doğru kalitede ve özelliklerde, doğru miktarda ve doğru zamanda teslim eder. Bu da konaklama işletmelerin hizmet sürecinin aksamamasını ve optimum maliyet ile ürün tedarik etmesini sağlayacaktır (Tellioğlu ve Etlioğlu, 2019, s. 147).

Ünal ve diğerleri (2019), otel işletmelerinde tedarikçi seçiminde Bulanık Analitik Hiyerarşi Süreci (BAHP) yönteminden elde edilen ağırlıkların kullanıldığı Hedef Programlama yöntemi ile uygun tedarikçi seçimi problemini el almışlardır. Tedarikçi seçiminde 5 ana kriter ve 9 alt kriter kullanmışlardır. En önemli kriterin ürün kalitesi olduğu (\%34), Fiyatın ise ikinci sırada geldiği (\%23) görülmüştür. Ayrıca Tedarikçi performansı kriteri içerisinde ise satış sonrası destek kriterinin diğer alt kriterlerle karşılaştırıldığında daha önemli bulunduğu ortaya çıkmıştır.

\section{Yöntem ve bulgular}

\section{Bulanık analitik hiyerarşi süreci}

AHP uygulaması olarak literatürde çeşitli uygulamalar bulunmaktadır. Farklı AHP yaklaşımlarının çalışmalarda uygulandığı gözlemlenmektedir. Çok ölçütlü değerlendirmelerde en iyi seçeneği tespit etmek ve sıralamak amacıyla bulanık kümeler teorisi ve hiyerarşik yapı yöntemlerini birçok araştırmacılar tarafından uygulamışlardır. Bulanık küme teorisinde insan düşüncelerinde ve yargılarında belirsizlik bulunmaktadır Zadeh (1965). Araştırma amacı doğrultusunda ikili mukayese süreçlerinde karar vericiler sözel olarak bilgiler verirken sabit değerler sunmaktan ziyade bir aralık doğrusunda bilgi vermektedirler. Bunun nedeni ise süreçlerin mukayese açısından bulanıklık göstermesinden kaynaklanmaktadır. Bu veri sunuş metotları kullanılarak bulanık küme kuramı ve hiyerarşik yapı analizi ile alternatiflerin ölçeklendirilmesine yönelik yöntemler geliştirilmiştir.

Bulanık küme teorisinde bir ifadeye göre karar vericilerin değerlendirmesinde kesin değerler içeren AHP yöntemine göre kümeye ait derecelerin (p) 0 ile 1 arasında değişen bulanık değerler kullanılarak kararlara etki eden belirsizliklerin sayısallaştırılmasıyla daha doğru sonuçlara ulaşılabilmektedir (Buckley, 1985).

Bulanıklığı ifade eden işaret “ " sembolü ile gösterilmekte vebirbulanık kümeiçerisindeki tüm değerler, o kümeye ne derecede ait olunduğu veya olunmadığı açısından ifade edilmektedir (Lee, Chen ve Chang, 2008, s. 98). Bulanık AHP tekniği, ikili karşılaştırma çalışmalarında kullanılan bulanık AHP tekniği sözel ifadenin bulanık sayılar ile ifade edilmesi mantığı temelinde karar vericilere esneklik sunmaktadır. Bulanık AHP tekniği için izlenecek sayısallaşma ve hesaplamada; Buckley (1985) Geometrik Ortalama Tekniğini, Liou ve Wang (1992) Toplam İntegral Değer Tekniğini, Chang (1996) Genişletilmiş Analiz Tekniği ve Abdel-Kader ve Dugdale (2001)'in Sıralama Tekniğini kullanmışlardır.

Bu çalışmada Bulanık AHP analizinde Buckley'in Geometrik Ortalama Tekniği uygulanmıştır. Bulanık AHP analizi kapsamında karşılaştırılan kriter/alternatiflerin sözel ifadelerinin karşılığında üçgensel bulanık sayılar kullanılmakta ve bu sayılar, $l$ en düşük, $m$ orta, $u$ ise üst sınır olmak üzere üç reel sayı ile ifade edilmektedir. Bulanık AHP değerlendirme ölçeği Tablo 1'de görülmektedir. 
Tablo 1: Bulanık AHP Değerlendirme Ölçeği

\begin{tabular}{|c|c|c|}
\hline Önem Derecesi (Dilsel İfadeler) & $\begin{array}{c}\text { Üçgensel Bulanık Sayılar } \\
(l, m, u)\end{array}$ & $\begin{array}{c}\text { Üçgensel Karşılık Bulanık Sayılar } \\
(h u, h m, 171)\end{array}$ \\
\hline Eşit Önemli & $(1,1,1)$ & $(1 / 1,1 / 1,1 / 1)$ \\
\hline Biraz Önemli & $(2,3,4)$ & $(1 / 4,1 / 3,1 / 2)$ \\
\hline Önemli & $(4,5,6)$ & $(1 / 6,1 / 5,1 / 4)$ \\
\hline Oldukça Önemli & $(6,7,8)$ & $(1 / 9,1 / 9,1 / 7,1 / 6)$ \\
\hline Mutlak Önemli & $(8,9,9)$ & \\
\hline
\end{tabular}

Kaynak: Kazançoğlu ve Öztürkoğlu, 2018.

Geometrik Ortalama Tekniğine göre bu çalışmada uygulanan adımlar şunlardır (Kazançoğlu ve Özturkoğlu, 2018, s. 183):

Adım 1 Karşılaștırma Matrislerinin Olușturulması: Karar vericiler tarafından dilsel değişkenler üzerinden yapılan ikili karşılaştırmalar bulanık sayılara dönüştürülür ve bulanık karşılaştırma matrisi (Ãnxn) oluşturulur.

$$
\left[\begin{array}{cccc}
1 & \tilde{a}_{12} & \cdots & \tilde{a}_{1 n} \\
\tilde{a} & 1 & \cdots & \tilde{a}_{2 n} \\
\vdots & \vdots & \ddots & \vdots \\
\tilde{a}_{n 1} & \tilde{a}_{n 2} & \cdots & 1
\end{array}\right]=\left[\begin{array}{cccc}
1 & \tilde{a}_{12} & \cdots & \tilde{a}_{1 n} \\
1 / \tilde{a}_{12} & 1 & \cdots & \tilde{a}_{2 n} \\
\vdots & \vdots & \ddots & \vdots \\
1 / \tilde{a}_{1 n} & 1 / \tilde{a}_{2 n} & \cdots & 1
\end{array}\right]
$$

Birden çok karar vericinin söz konusu olduğunda ortak matris oluşturularak işlemlere devam edilir. Her bir karar verici için oluşturulan matrislerin birleştirilmesi işlemi her bir hücredeki bulanık değerin sırasıyla geometrik ortalamasının alınmasıyla gerçekleştirilir (Meixner, 2009). Bu şekilde matrislere ait (lij, mij ve uij ) değerleriyle uzman grubu ait ortak bir $(\hat{A})$ matrisine dönüştürülmüş olur.

$$
l_{i j}=\left(\prod_{k=1}^{k}\left(l_{i j k}\right)^{1 / k}, m_{i j}=\left(\prod_{k=1}^{k}\left(m_{i j k}\right)^{1 / k}, u_{i j}=\left(\prod_{k=1}^{k}\left(u_{i j k}\right)^{1 / k}\right.\right.\right.
$$

Adım 2 Bulanık Değerlerin Geometrik Ortalamasının Alınması: Bulanıkkarşılaştırmadeğerleriningeometrik ortalaması(ri) hesaplanır. Bu işlem şu şekilde hesaplanır:

$$
\tilde{r}_{i}=\left(\tilde{a}_{i 1} \times \cdots \times \tilde{a}_{i j} \times \cdots \times \tilde{a}_{i n}\right)^{1 / n}
$$

Adım 3 Geometrik Ortalamaların Bulanık Ağırlıklara Dönüștürülmesi: Her bir ri değeri için vektör toplamı hesaplanır ve toplanan vektörlerin (-1)'inci kuvveti alınır. Ortaya çıkan sonuçlar artan bir sıralama oluşturacak şekilde düzenlenir. Son olacakta bulanık ağırlık değeri (wi ) için her bir ri değeri ters vektör ile çarpılır. Bu işlem şu şekilde hesaplanır:

$$
\widetilde{w}_{i}=\tilde{r}_{i} \times\left[\tilde{r}_{1}+\cdots+\tilde{r}_{i}+\cdots+\tilde{r}_{n}\right]^{-1}
$$

Adım 4 Bulanıklıktan Arındırma: Adım 3'te elde edilen kriter ağırlıkları bulanık üçgen sayılar olduğundan, Alan Merkezi (Center of Area) yöntemiyle bulanıklıktan arındırılmaları sağlanarak En İyi Bulanık Olmayan Performans değeri (Best Non-fuzy Performance value-BNP) hesaplanır. Bu işlem şu şekilde hesaplanır:

$$
B N P_{w i}=\left[\left(U_{w i}-L_{w i}\right)+\left(M_{w i}-L_{w i}\right)\right] / 3+L_{w i}
$$

Adım 5: Adım 4'te elde edilen değerler bulanıklıktan arındırılmış değerler olsa da normalize edilmesi gerekmektedir. Bulanık AHP analizi sonucunda ulaşılmak istenen normalize edilmiş asıl değeri (Ni) vermektedir. Bu işlem şu şekilde hesaplanır:

$$
N_{i}=\frac{B N P_{w i}}{\sum_{i=1}^{n} B N P_{w i}}
$$




\section{Bulanık AHP ile tedarikçi firmaların performansının ölçülmesi}

İçerik analizinden sonra sektörden satın alma uzmanları ile yarı yapılandırılmış sorularla nitel görüşme yapılmıştır. Burada amaç pandemi sürecinde konaklama sektöründe gıda tedariki sağlayan tedarikçilerin performans değerlendirmesinde ön plana çıan kriterlerin belirlenmesidir. Sektörden satın alma uzmanlarından elde edilen bilgiler çözümlenerek nitel analize tabi tutulmuş ve bu araştırmanın ana kriterleri ile alt kriterleri oluşturulmuştur.

Görüşmelerde pandemi sürecinde sektörde yaşanan daralma ile tedarik piyasasında önemli değişimlerin yaşandığı vurgulanmıştır. Bu süreçte daha az stokla tam zamanında sevkiyatlarla tedarik sağlandığı bunun neticesinde de emniyet stoklarının yönetilmesi kritik hale geldiği belirtilmiştir. Uzmanlar pandemi öncesinde kalite, fiyat önemli iken bu süreçle beraber esneklik, teslimat ve hijyenin kriterlerinin önem kazandığı belirtilmiştir. Nitel analizde elde edilen ana kriterler ve buna göre belirlenen alt kriterler aşağıdaki gibidir:

- $\quad$ Fiyat: Fiyat uygunluğu, miktar indirimi, ödeme yaklaşımı

- Kalite: Ürün kalitesi, ret/iade oranı, süreçlerin kalitesi, sipariş süreçlerinin kalitesi

- Teslimat: Doğru ürün/miktar teslimatı, tam zamanında doğru teslimat, paketleme ve nakliye performansi

- Esneklik: Değişikliklere cevap verme, acil durumlara çözüm üretme, ürün/zaman/miktar karşılama, acil talepleri karşılama esnekliği

- Tedarikçi Profili: sürdürülebilirlik, iletişim/çalışanların yaklaşımı, kapasite/ürün çeşitliliği, güvenilirlik, stratejik uyum/işbirliği, yenilikçi olma

- Pandemi Yaklaşımı: Dağıtım hijyeni, ürün ve işletme hijyeni, işletme/çalışanların pandemi kurallarına yaklaşımı

Bu kriterler kullanılarak hazırlanan nicel değerlendirme formu; Adana ilinde 5 yıldızlı bir konaklama işletmesinin satın alma müdürü ile yapılan mülakatla doldurulmuş olup Şekil 1'deki hiyerarşik yapıya göre bulanık AHP analiz yöntemi kullanılarak değerlendirilmiştir. Pandemi sürecinde işletmenin gıda tedarikini yoğun olarak sağlayan 3 tedarikçisi değerlendirilerek performansları ölçülmüştür.

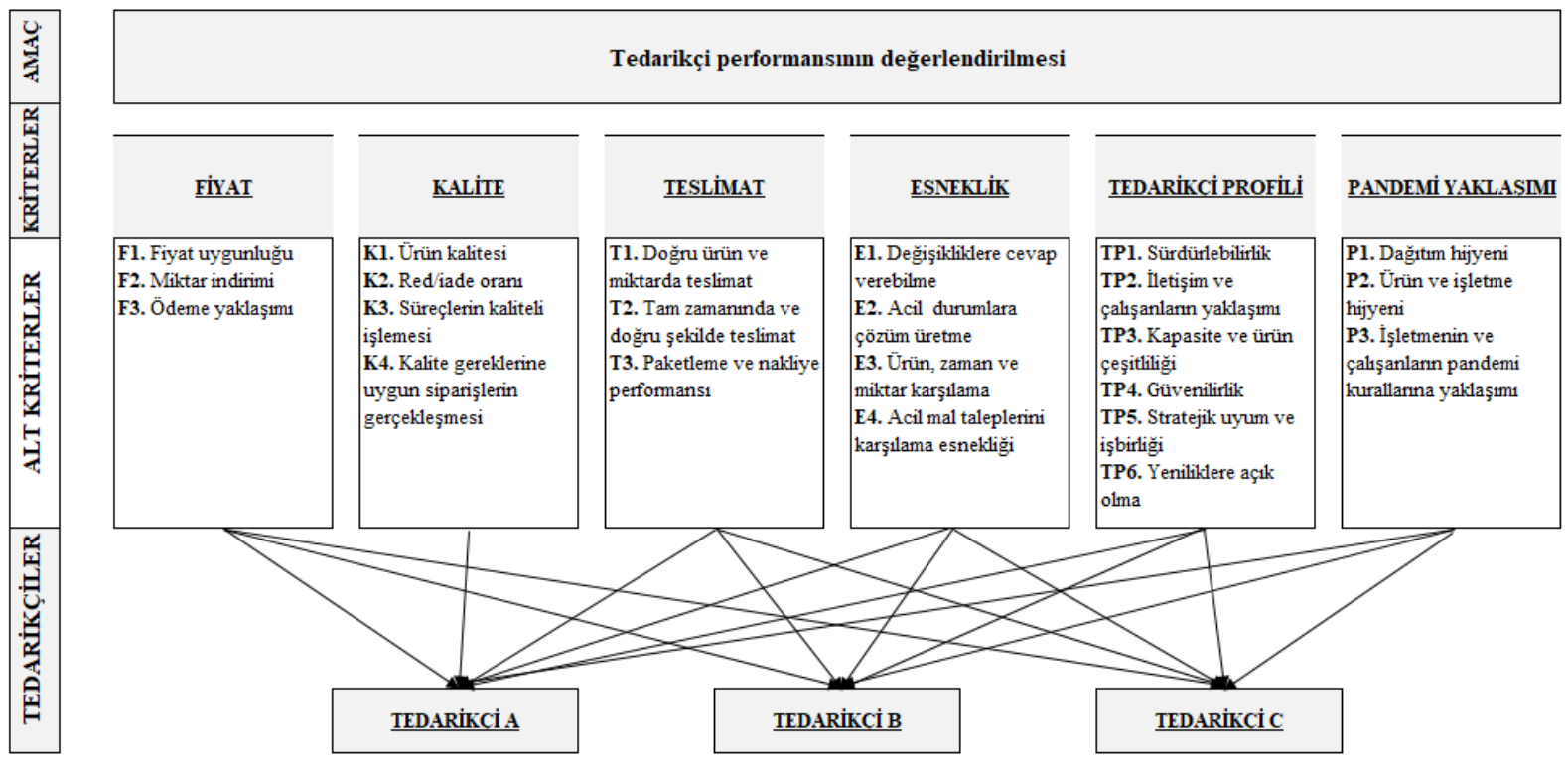

Şekil 1: AHP Hiyerarşisi

Kaynak: Yazar tarafından üretilmiştir. 
TEDARİKÇİ A'ya ait alt kriterlerin bulanık karşılaştırmalar matrisleri

Tablo 2: Fiyata Göre Bulanık Karşılaştırma Matrisi

\begin{tabular}{cccc}
\hline FiYAT & F1 & F2 & F3 \\
\hline F1 & $1,1,1$ & $6,7,8$ & $1 / 6,1 / 5,1 / 4$ \\
\hline F2 & $1 / 8,1 / 7,1 / 6$ & $1,1,1$ & $1 / 6,1 / 5,1 / 4$ \\
\hline F3 & $4,5,6$ & $4,5,6$ & $1,1,1$ \\
\hline
\end{tabular}

Tablo 4: Teslimata Göre Bulanık Karşılaştırma Matrisi

\begin{tabular}{cccc}
\hline TESLIMAT & T1 & T2 & T3 \\
\hline T1 & $1,1,1$ & $2,3,4$ & $1 / 6,1 / 5,1 / 4$ \\
\hline T2 & $1 / 4,1 / 3,1 / 2$ & $1,1,1$ & $1 / 6,1 / 5,1 / 4$ \\
\hline T3 & $4,5,6$ & $4,5,6$ & $1,1,1$ \\
\hline
\end{tabular}

Tablo 6: Tedarikçi Profiline Göre Bulanık Karşılaştırma Matrisi

\begin{tabular}{ccccccc}
\hline T.PROFIL & TP1 & TP2 & TP3 & TP4 & TP5 & TP6 \\
\hline TP1 & $1,1,1$ & $1 / 4,1 / 3,1 / 2$ & $1 / 8,1 / 7,1 / 6$ & $1 / 8,1 / 7,1 / 6$ & $1,1,1$ & $4,5,6$ \\
\hline TP2 & $2,3,4$ & $1,1,1$ & $1,1,1$ & $1,1,1$ & $4,5,6$ & $6,7,8$ \\
\hline TP3 & $6,7,8$ & $1,1,1$ & $1,1,1$ & $1,1,1$ & $4,5,6$ & $4,5,6$ \\
\hline TP4 & $6,7,8$ & $1,1,1$ & $1,1,1$ & $1,1,1$ & $2,3,4$ & $1,1,1$ \\
\hline TP5 & $1,1,1$ & $1 / 6,1 / 5,1 / 4$ & $1 / 6,1 / 5,1 / 4$ & $1 / 4,1 / 3,1 / 2$ & $1,1,1$ & $1,1,1$ \\
\hline TP6 & $1 / 6,1 / 5,1 / 4$ & $1 / 8,1 / 7,1 / 6$ & $1 / 6,1 / 5,1 / 4$ & $1,1,1$ & $1,1,1$ & $1,1,1$ \\
\hline
\end{tabular}

Tablo 7: Pandemi Yaklaşımına Göre Bulanık Karşılaştırma Matrisi

\begin{tabular}{cccc}
\hline PANDEMI & P1 & P2 & P3 \\
\hline $\mathbf{P 1}$ & $1,1,1$ & $1 / 8,1 / 7,1 / 6$ & $1 / 6,1 / 5,1 / 4$ \\
\hline $\mathbf{P 2}$ & $6,7,8$ & $1,1,1$ & $1,1,1$ \\
\hline $\mathbf{P 3}$ & $4,5,6$ & $1,1,1$ & $1,1,1$ \\
\hline
\end{tabular}


Tedarikçi A'ya ait en yüksek performans ana kriteriler belirleme amacına yönelik olarak bulanık ikili karşılaştırma matrisi Tablo 2 ile Tablo 7 arasında verilmiştir. Bu tablolar yardımıyla, ayrıntılı olarak açıklanan bulanık AHP analizi yöntemi kullanılıp ă̆ırlık vektörleri elde edilmiş ve performans ana kriterlerine ait önem ağırlıklarına ulaşılmıştır.

Tablo 8: TEDARİKÇİ A'nın Bulanık Değerlendirme Sonuçları

\begin{tabular}{|c|c|c|c|c|c|c|c|c|c|}
\hline FİYAT & & $\mathrm{ri}$ & & & $\mathrm{w} i$ & & Mi & $\mathrm{Ni}$ & Rank \\
\hline F1 & 1,000 & 1,119 & 1,260 & 0,204 & 0,257 & 0,333 & 0,265 & 0,259 & 2 \\
\hline F2 & 0,275 & 0,306 & 0,347 & 0,056 & 0,070 & 0,092 & 0,073 & 0,071 & 3 \\
\hline F3 & 2,520 & 2,924 & 3,302 & 0,514 & 0,673 & 0,872 & 0,686 & 0,670 & 1 \\
\hline \multicolumn{10}{|c|}{$\boldsymbol{P ( - 1 )}[0,264 ; 0,230 ; 0,204]$} \\
\hline KALİTE & & $\mathrm{ri}$ & & & $\mathrm{w} i$ & & Mi & $\mathrm{Ni}$ & Rank \\
\hline K1 & 0,904 & 1,000 & 1,107 & 0,163 & 0,195 & 0,235 & 0,197 & 0,196 & 3 \\
\hline K2 & 0,243 & 0,275 & 0,319 & 0,044 & 0,054 & 0,068 & 0,055 & 0,055 & 4 \\
\hline K3 & 1,565 & 1,627 & 1,682 & 0,282 & 0,317 & 0,357 & 0,318 & 0,316 & 2 \\
\hline K4 & 2,000 & 2,236 & 2,449 & 0,360 & 0,436 & 0,519 & 0,438 & 0,434 & 1 \\
\hline \multicolumn{10}{|c|}{$\boldsymbol{P ( - 1 )}[0,212 ; 0,195 ; 0,180]$} \\
\hline TESLİMAT & & $\mathrm{ri}$ & & & $\mathrm{w} i$ & & Mi & $\mathrm{Ni}$ & Rank \\
\hline T1 & 0,693 & 0,843 & 1,000 & 0,144 & 0,202 & 0,281 & 0,209 & 0,203 & 2 \\
\hline $\mathbf{T} 2$ & 0,347 & 0,405 & 0,500 & 0,072 & 0,097 & 0,141 & 0,103 & 0,100 & 3 \\
\hline T3 & 2,520 & 2,924 & 3,302 & 0,524 & 0,702 & 0,928 & 0,718 & 0,697 & 1 \\
\hline \multicolumn{10}{|c|}{$\boldsymbol{P ( - 1 )}[0,186 ; 0,166 ; 0,149]$} \\
\hline ESNEKLİK & & $\mathrm{ri}$ & & & wi & & Mi & $\mathbf{N i}$ & Rank \\
\hline E1 & 0,639 & 0,669 & 0,707 & 0,095 & 0,111 & 0,132 & 0,113 & 0,111 & 3 \\
\hline E2 & 0,380 & 0,411 & 0,452 & 0,057 & 0,068 & 0,084 & 0,070 & 0,069 & 4 \\
\hline E3 & 3,464 & 3,956 & 4,427 & 0,516 & 0,657 & 0,823 & 0,665 & 0,655 & 1 \\
\hline E4 & 0,904 & 1,000 & 1,107 & 0,135 & 0,166 & 0,206 & 0,169 & 0,166 & 2 \\
\hline \multicolumn{10}{|c|}{$\boldsymbol{P ( - 1 )}[0,186 ; 0,166 ; 0,149]$} \\
\hline T.PROFİL & & $\mathrm{ri}$ & & & wi & & Mi & $\mathbf{N i}$ & Rank \\
\hline TP1 & 0,500 & 0,569 & 0,641 & 0,060 & 0,074 & 0,093 & 0,075 & 0,075 & 4 \\
\hline TP2 & 1,906 & 2,172 & 2,402 & 0,227 & 0,282 & 0,348 & 0,286 & 0,282 & 2 \\
\hline TP3 & 2,140 & 2,365 & 2,570 & 0,255 & 0,307 & 0,373 & 0,312 & 0,308 & 1 \\
\hline TP4 & 1,513 & 1,661 & 1,782 & 0,180 & 0,216 & 0,258 & 0,218 & 0,215 & 3 \\
\hline TP5 & 0,437 & 0,487 & 0,561 & 0,052 & 0,063 & 0,081 & 0,066 & 0,065 & 5 \\
\hline TP6 & 0,389 & 0,423 & 0,467 & 0,046 & 0,055 & 0,068 & 0,056 & 0,056 & 6 \\
\hline
\end{tabular}




\begin{tabular}{|c|c|c|c|c|c|c|c|c|c|}
\hline & \multicolumn{9}{|c|}{$P(-1)[0,145 ; 0,130 ; 0,119]$} \\
\hline PANDEMİ & & $\mathrm{ri}$ & & & $\mathrm{w} i$ & & Mi & $\mathbf{N i}$ & Rank \\
\hline P1 & 0,275 & 0,306 & 0,347 & 0,066 & 0,078 & 0,094 & 0,079 & 0,079 & 3 \\
\hline P2 & 1,817 & 1,913 & 2,000 & 0,436 & 0,488 & 0,544 & 0,489 & 0,486 & 1 \\
\hline \multirow[t]{2}{*}{ P3 } & 1,587 & 1,710 & 1,817 & 0,381 & 0,436 & 0,494 & 0,437 & 0,435 & 2 \\
\hline & \multicolumn{9}{|c|}{$\boldsymbol{P ( - 1 )}[0,272 ; 0,255 ; 0,240]$} \\
\hline ANA KRİTER & \multicolumn{4}{|c|}{$\mathrm{ri}$} & \multicolumn{2}{|l|}{ wi } & Mi & $\mathbf{N i}$ & Rank \\
\hline FIYYAT & 0,294 & 0,333 & 0,389 & 0,032 & 0,042 & 0,058 & 0,075 & 0,075 & 4 \\
\hline KALITTE & 2,402 & 2,840 & 3,238 & 0,264 & 0,361 & 0,482 & 0,286 & 0,282 & 2 \\
\hline TESLIMAT & 0,364 & 0,423 & 0,500 & 0,040 & 0,054 & 0,075 & 0,312 & 0,308 & 1 \\
\hline ESNEKLİK & 1,513 & 1,757 & 2,000 & 0,166 & 0,223 & 0,298 & 0,218 & 0,215 & 3 \\
\hline TED.PROFILİ & 1,414 & 1,710 & 2,040 & 0,156 & 0,217 & 0,304 & 0,066 & 0,065 & 5 \\
\hline \multirow[t]{2}{*}{ PANDEMİ YAK. } & 0,742 & 0,833 & 0,953 & 0,082 & 0,106 & 0,142 & 0,056 & 0,056 & 6 \\
\hline & \multicolumn{9}{|c|}{$P(-1)[0,149 ; 0,127 ; 0,110]$} \\
\hline
\end{tabular}

Hesaplamalar sonucu Tablo 8'de Tedarikçi A'nın ödeme yaklaşımı (F3), kalite gereklerine uygun siparişleri gerçekleştirme (K4), paketleme-nakliye performansı (T3), ürün-zaman-miktar karşılama (E3), kapasite-ürün çeşitliliği (TP3), ürün-işletme hijyeni (P2) performans alt kriterlerinin yüksek olduğu gözlemlenirken ana kriterlerinin karşılaştırmasında ise öncelikli olarak teslimat performansının ilk sırada olduğu belirlenmiştir. 
TEDARİKÇİ B'ye ait alt kriterlerin bulanık karşılaştırmalar matrisleri

Tablo 9: Fiyat Göre Bulanık Karşılaştırma

Matrisi

\begin{tabular}{cccc}
\hline FIYAT & F1 & F2 & F3 \\
\hline F1 & $1,1,1$ & $1 / 6,1 / 5,1 / 4$ & $1,1,1$ \\
\hline F2 & $4,5,6$ & $1,1,1$ & $4,5,6$ \\
\hline F3 & $1,1,1$ & $1 / 6,1 / 5,1 / 4$ & $1,1,1$ \\
\hline
\end{tabular}

Tablo 11: Teslimata Göre Bulanık Karşılaştırma Matrisi

\begin{tabular}{cccc}
\hline TESLIMAT & T1 & T2 & T3 \\
\hline T1 & $1,1,1$ & $4,5,6$ & $1,1,1$ \\
\hline T2 & $1 / 6,1 / 5,1 / 4$ & $1,1,1$ & $1 / 4,1 / 3,1 / 2$ \\
\hline & $1,1,1$ & $2,3,4$ & $1,1,1$ \\
\hline
\end{tabular}

\begin{tabular}{ccccccc}
\hline T.PROFIL & TP1 & TP2 & TP3 & TP4 & TP5 & TP6 \\
\hline TP1 & $1,1,1$ & $1 / 6,1 / 5,1 / 4$ & $1 / 6,1 / 5,1 / 4$ & $1 / 8,1 / 7,1 / 6$ & $1 / 6,1 / 5,1 / 4$ & $\begin{array}{c}1 / 8,1 / 7,1 / \\
6\end{array}$ \\
\hline TP2 & $4,5,6$ & $1,1,1$ & $1,1,1$ & $1,1,1$ & $1,1,1$ & $\begin{array}{c}1 / 6,1 / 5,1 / \\
4\end{array}$ \\
\hline TP3 & $4,5,6$ & $1,1,1$ & $1,1,1$ & $1,1,1$ & $4,5,6$ & $\begin{array}{c}1 / 6,1 / 5,1 / \\
4\end{array}$ \\
\hline TP4 & $6,7,8$ & $1,1,1$ & $1,1,1$ & $1,1,1$ & $1,1,1$ & $1,1,1$ \\
\hline TP5 & $4,5,6$ & $1,1,1$ & $1 / 6,1 / 5,1 / 4$ & $1,1,1$ & $1,1,1$ & $1 / 4,1 / 3,1 /$ \\
TP6 & $6,7,8$ & $4,5,6$ & $4,5,6$ & $1,1,1$ & $2,3,4$ & $1,1,1$ \\
\hline
\end{tabular}

Tablo 14: Pandemi Yaklaşımına Göre Bulanık Karşılaştırma Matrisi

\begin{tabular}{cccc} 
PANDEMI & P1 & P2 & P3 \\
\hline P1 & $1,1,1$ & $1,1,1$ & $1 / 6,1 / 5,1 / 4$ \\
\hline P2 & $1,1,1$ & $1,1,1$ & $1,1,1$ \\
\hline P3 & $4,5,6$ & $1,1,1$ & $1,1,1$ \\
\hline
\end{tabular}


Tedarikçi B'ye ait en yüksek performans ana kriteriler belirleme amacına yönelik olarak bulanık ikili karşılaştırma matrisi Tablo 9 ile Tablo 14 arasında verilmiştir. Bu tablolar yardımıyla, ayrıntılı olarak açıklanan bulanık AHP analizi yöntemi kullanılıp ağırlık vektörleri elde edilmiş ve Tablo 15'de performans ana kriterlerine ait ikili karşılaştırma matrisine ulaşılmıştır.

Tablo 15: Ana Kriterlere Göre Tedarikçi B’nin Bulanık Karşılaştırma Matrisi

\begin{tabular}{ccccccc}
\hline ANA KRITER & $\mathbf{F}$ & $\mathbf{K}$ & $\mathbf{T}$ & $\mathbf{E}$ & $\mathbf{T P}$ & $\mathbf{P}$ \\
\hline $\mathbf{F}$ & $1,1,1$ & $1 / 8,1 / 7,1 / 6$ & $4,5,6$ & $1 / 8,1 / 7,1 / 6$ & $1 / 6,1 / 5,1 / 4$ & $1,1,1$ \\
\hline $\mathbf{K}$ & $6,7,8$ & $1,1,1$ & $6,7,8$ & $1 / 6,1 / 5,1 / 4$ & $1 / 6,1 / 5,1 / 4$ & $1,1,1$ \\
\hline $\mathbf{T}$ & $1 / 6,1 / 5,1 / 4$ & $1 / 8,1 / 7,1 / 6$ & $1,1,1$ & $1 / 6,1 / 5,1 / 4$ & $1 / 8,1 / 7,1 / 6$ & $1,1,1$ \\
\hline $\mathbf{E}$ & $6,7,8$ & $4,5,6$ & $4,5,6$ & $1,1,1$ & $1 / 4,1 / 3,1 / 2$ & $1,1,1$ \\
\hline TP & $4,5,6$ & $4,5,6$ & $6,7,8$ & $2,3,4$ & $1,1,1$ & $1,1,1$ \\
\hline $\mathbf{P}$ & $1,1,1$ & $1,1,1$ & $1,1,1$ & $1,1,1$ & $1,1,1$ & $1,1,1$ \\
\hline
\end{tabular}

Tedarikçi B'ye ait performans kriterlerinin karşılaştırma matrislerinin belirlenen yönteme göre bulanık $\mathrm{AHP}^{\prime}$ de izlenecek Adım 2,3,4 ve 5 işlemlerine tabi tutulmuştur. Verilerin işlenmesi ile elde edilen değerlendirme sonuçları (ri, wi, Mi, Ni) Tablo $16^{\prime}$ da ayrı ayrı verilmiş olup ana ve alt kriterlere ait performans ağırlık değerlerine (Rank) ulaşılmıştır.

Tablo 16: TEDARİKÇİ B'nın Bulanık Değerlendirme Sonuçları

\begin{tabular}{|c|c|c|c|c|c|c|c|c|c|}
\hline FIYAT & & $\mathrm{ri}$ & & & wi & & Mi & $\mathbf{N i}$ & Rank \\
\hline F1 & 0,550 & 0,585 & 0,630 & 0,121 & 0,143 & 0,174 & 0,146 & 0,143 & 2 \\
\hline F2 & 2,520 & 2,924 & 3,302 & 0,552 & 0,713 & 0,911 & 0,726 & 0,713 & 3 \\
\hline \multirow[t]{2}{*}{ F3 } & 0,550 & 0,585 & 0,630 & 0,121 & 0,143 & 0,174 & 0,146 & 0,143 & 1 \\
\hline & \multicolumn{6}{|c|}{$\boldsymbol{P}(-1)[0,276 ; 0,244 ; 0,219]$} & & & \\
\hline KALITE & \multicolumn{3}{|c|}{$\mathrm{ri}$} & \multicolumn{3}{|c|}{$\mathrm{w} i$} & Mi & $\mathbf{N i}$ & Rank \\
\hline K1 & 0,595 & 0,669 & 0,760 & 0,094 & 0,115 & 0,144 & 0,118 & 0,117 & 3 \\
\hline K2 & 0,226 & 0,253 & 0,289 & 0,036 & 0,043 & 0,055 & 0,045 & 0,044 & 4 \\
\hline K3 & 2,000 & 2,236 & 2,449 & 0,316 & 0,385 & 0,465 & 0,389 & 0,384 & 2 \\
\hline \multirow[t]{2}{*}{ K4 } & 2,449 & 2,646 & 2,828 & 0,387 & 0,455 & 0,537 & 0,460 & 0,455 & 1 \\
\hline & \multicolumn{6}{|c|}{$P(-1)[0,190 ; 0,172 ; 0,158]$} & & & \\
\hline TESLIMMAT & & $\mathrm{ri}$ & & & wi & & Mi & $\mathbf{N i}$ & Rank \\
\hline T1 & 1,587 & 1,710 & 1,817 & 0,406 & 0,481 & 0,569 & 0,485 & 0,479 & 2 \\
\hline $\mathrm{T} 2$ & 0,347 & 0,405 & 0,500 & 0,089 & 0,114 & 0,157 & 0,120 & 0,118 & 3 \\
\hline \multirow[t]{2}{*}{ T3 } & 1,260 & 1,442 & 1,587 & 0,323 & 0,405 & 0,497 & 0,408 & 0,403 & 1 \\
\hline & \multicolumn{6}{|c|}{$P(-1)[0,186 ; 0,166 ; 0,149]$} & & & \\
\hline ESNEKLİK & & $\mathrm{ri}$ & & & wi & & Mi & $\mathbf{N i}$ & Rank \\
\hline
\end{tabular}


Serbülent Kapıcı \& İsmail Güçlü \& Yusuf Emre Karakaş

\begin{tabular}{|c|c|c|c|c|c|c|c|c|c|}
\hline E1 & 0,420 & 0,467 & 0,537 & 0,071 & 0,088 & 0,114 & 0,091 & 0,090 & 3 \\
\hline E2 & 2,213 & 2,432 & 2,632 & 0,376 & 0,457 & 0,558 & 0,464 & 0,456 & 1 \\
\hline E3 & 0,408 & 0,447 & 0,500 & 0,069 & 0,084 & 0,106 & 0,086 & 0,085 & 4 \\
\hline E4 & 1,682 & 1,968 & 2,213 & 0,286 & 0,370 & 0,469 & 0,375 & 0,369 & 2 \\
\hline \multicolumn{10}{|c|}{$P(-1)[0,212 ; 0,188 ; 0,170]$} \\
\hline T.PROFIL & & $\mathrm{ri}$ & & & wi & & Mi & $\mathrm{Ni}$ & Rank \\
\hline TP1 & 0,195 & 0,221 & 0,257 & 0,023 & 0,029 & 0,038 & 0,030 & 0,030 & 6 \\
\hline TP2 & 0,935 & 1,000 & 1,070 & 0,112 & 0,132 & 0,157 & 0,134 & 0,132 & 4 \\
\hline TP3 & 1,178 & 1,308 & 1,442 & 0,141 & 0,173 & 0,212 & 0,175 & 0,173 & 3 \\
\hline TP4 & 1,348 & 1,383 & 1,414 & 0,162 & 0,183 & 0,208 & 0,184 & 0,182 & 2 \\
\hline TP5 & 0,742 & 0,833 & 0,891 & 0,089 & 0,110 & 0,131 & 0,110 & 0,109 & 5 \\
\hline TP6 & 2,402 & 2,840 & 3,238 & 0,288 & 0,375 & 0,476 & 0,380 & 0,375 & 1 \\
\hline \multicolumn{10}{|c|}{$P(-1)[0,147 ; 0,132 ; 0,120]$} \\
\hline PANDEMI & & $\mathrm{ri}$ & & & $\mathbf{w} i$ & & Mi & $\mathrm{Ni}$ & Rank \\
\hline P1 & 0,550 & 0,585 & 0,630 & 0,132 & 0,149 & 0,171 & 0,151 & 0,179 & 3 \\
\hline P2 & 1,000 & 1,000 & 1,000 & 0,240 & 0,255 & 0,272 & 0,256 & 0,303 & 2 \\
\hline P3 & 1,587 & 1,710 & 1,817 & 0,381 & 0,436 & 0,494 & 0,437 & 0,518 & 1 \\
\hline \multicolumn{10}{|c|}{$\boldsymbol{P}(-1)[0,319 ; 0,304 ; 0,290]$} \\
\hline ANA KRİTER & & $\mathrm{ri}$ & & & wi & & Mi & $\mathrm{Ni}$ & Rank \\
\hline FIYAT & 0,467 & 0,523 & 0,589 & 0,054 & 0,067 & 0,086 & 0,069 & 0,068 & 5 \\
\hline KALİTE & 1,000 & 1,119 & 1,260 & 0,115 & 0,144 & 0,184 & 0,148 & 0,145 & 3 \\
\hline TESLIMAT & 0,275 & 0,306 & 0,347 & 0,032 & 0,039 & 0,051 & 0,041 & 0,040 & 6 \\
\hline ESNEKLİK & 1,698 & 1,969 & 2,289 & 0,195 & 0,254 & 0,334 & 0,261 & 0,256 & 2 \\
\hline TED.PROFİLI & 2,402 & 2,840 & 3,238 & 0,276 & 0,366 & 0,473 & 0,372 & 0,364 & 1 \\
\hline PAND. YAK. & 1,000 & 1,000 & 1,000 & 0,115 & 0,129 & 0,146 & 0,130 & 0,127 & 4 \\
\hline
\end{tabular}

$P(-1)[0,146 ; 0,129 ; 0,115]$

Hesaplamalar sonucu Tablo 16'da Tedarikçi B’nın ödeme yaklaşımı (F3), kalite gereklerine uygun siparişleri gerçekleştirme (K4), paketleme-nakliye performansı (T3), acil durumlara çözüm üretme (E2), yeniliklere açık olma (TP6), işletmenin ve çalışanların pandemi kurallarına yaklaşımı (P3) performans alt kriterlerinin yüksek olduğu gözlemlenirken ana kriterlerinin karşılaştırmasında ise öncelikli olarak tedarikçi profil performansının ilk sırada esnekliğin ikinci sırada olduğu belirlenmiştir.

Tedarikçi C'ye ait en yüksek performans alt kriterlerini belirleme amacına yönelik olarak bulanık ikili karşılaştırma matrisi Tablo 17 ile Tablo 22 arasında verilmiştir. Bu tablolar yardımıyla, ayrıntılı olarak açıklanan bulanık AHP analizi yöntemi kullanılıp ağırlık vektörleri elde edilmiş ve performans alt kriterlere ait birleşik önem ağırlıklarına ulaşılmıştır. 
TEDARİKÇİ C'ye ait alt kriterlerin bulanık karşılaştırmalar matrisleri

Tablo 17: Fiyata Göre Bulanık Karşılaştırma Matrisi

\begin{tabular}{cccc}
\hline FIYAT & F1 & F2 & F3 \\
\hline F1 & $1,1,1$ & $6,7,8$ & $1 / 6,1 / 5,1 / 4$ \\
\hline F2 & $1 / 8,1 / 7,1 / 6$ & $1,1,1$ & $1 / 6,1 / 5,1 / 4$ \\
\hline F3 & $4,5,6$ & $4,5,6$ & $1,1,1$ \\
\hline
\end{tabular}

Tablo 19: Teslimata Göre Bulanık Karşılaştırma Matrisi
Tablo 18: Kaliteye Göre Bulanık Karşılaştırma Matrisi

\begin{tabular}{|c|c|c|c|c|c|c|c|c|}
\hline TESLIMMAT & T1 & $\mathrm{T} 2$ & T3 & ESNEKLİK & E1 & E2 & E3 & E4 \\
\hline T1 & $1,1,1$ & $6,7,8$ & $4,5,6$ & E1 & $1,1,1$ & $1,1,1$ & $1 / 6,1 / 5,1 / 4$ & $1,1,1$ \\
\hline $\mathrm{T} 2$ & $1 / 8,1 / 7,1 / 6$ & $1,1,1$ & $1 / 6,1 / 5,1 / 4$ & E2 & $1,1,1$ & $1,1,1$ & $1 / 6,1 / 5,1 / 4$ & $1,1,1$ \\
\hline \multirow[t]{2}{*}{ T3 } & $1 / 6,1 / 5,1 / 4$ & $4,5,6$ & $1,1,1$ & E3 & $4,5,6$ & $4,5,6$ & $1,1,1$ & $6,7,8$ \\
\hline & & & & E4 & $1,1,1$ & $1,1,1$ & $1 / 8,1 / 7,1 / 6$ & $1,1,1$ \\
\hline
\end{tabular}

Tablo 21: Tedarikçi Profiline Göre Bulanık Karşılaştırma Matrisi

\begin{tabular}{ccccccc}
\hline T.PROFIL & TP1 & TP2 & TP3 & TP4 & TP5 & TP6 \\
\hline TP1 & $1,1,1$ & $4,5,6$ & $1 / 4,1 / 3,1 / 2$ & $1,1,1$ & $1,1,1$ & $4,5,6$ \\
\hline TP2 & $1 / 6,1 / 5,1 / 4$ & $1,1,1$ & $1 / 8,1 / 7,1 / 6$ & $1 / 8,1 / 7,1 / 6$ & $1 / 4,1 / 3,1 / 2$ & $6,7,8$ \\
\hline TP3 & $2,3,4$ & $6,7,5$ & $1,1,1$ & $1,1,1$ & $4,5,6$ & $1,1,1$ \\
\hline TP4 & $1,1,1$ & $6,7,8$ & $1,1,1$ & $1,1,1$ & $1,1,1$ & $4,5,6$ \\
\hline TP5 & $1,1,1$ & $2,3,4$ & $1 / 6,1 / 5,1 / 4$ & $1,1,1$ & $1,1,1$ & $6,7,8$ \\
\hline TP6 & $1 / 6,1 / 5,1 / 4$ & $1 / 8,1 / 7,1 / 6$ & $1,1,1$ & $1 / 6,1 / 5,1 / 4$ & $1 / 8,1 / 7,1 / 6$ & $1,1,1$ \\
\hline
\end{tabular}

Tablo 22: Pandemi Yaklaşımına Göre Bulanık Karşılaştırma Matrisi

\begin{tabular}{cccc}
\hline PANDEMI & $\mathbf{P 1}$ & $\mathbf{P 2}$ & $\mathbf{P 3}$ \\
\hline $\mathbf{P 1}$ & $1,1,1$ & $1,1,1$ & $1,1,1$ \\
\hline $\mathbf{P 2}$ & $1,1,1$ & $1,1,1$ & $1,1,1$ \\
\hline $\mathbf{P 3}$ & $1,1,1$ & $1,1,1$ & $1,1,1$ \\
\hline
\end{tabular}

Tedarikçi C'ye ait en yüksek performans ana kriteriler belirleme amacına yönelik olarak bulanık ikili karşılaştırma matrisi Tablo 23'te verilmiştir. Bu tablolar yardımıyla, ayrıntılı olarak açıklanan bulanık AHP analizi yöntemi kullanılıp ağırlık vektörleri elde edilmiş ve performans ana kriterlerine ait önem ağırlıklarına ulaşılmıştır. 
Tablo 23: Ana Kriterlere Göre Tedarikçi C'nin Bulanık Karşılaştırma Matrisi

\begin{tabular}{ccccccc}
\hline $\begin{array}{c}\text { ANA } \\
\text { KRITER }\end{array}$ & $\mathbf{F}$ & $\mathbf{K}$ & $\mathbf{T}$ & $\mathbf{E}$ & $\mathbf{T P}$ & $\mathbf{P}$ \\
\hline $\mathbf{F}$ & $1,1,1$ & $1 / 4,1 / 3,1 / 2$ & $6,7,8$ & $6,7,8$ & $4,5,6$ & $1,1,1$ \\
\hline $\mathbf{K}$ & $2,3,4$ & $1,1,1$ & $6,7,8$ & $4,5,6$ & $2,3,4$ & $1,1,1$ \\
\hline $\mathbf{T}$ & $1 / 8,1 / 7,1 / 6$ & $1 / 8,1 / 7,1 / 6$ & $1,1,1$ & $1 / 6,1 / 5,1 / 4$ & $1 / 8,1 / 7,1 / 6$ & $1 / 8,1 / 7,1 / 6$ \\
\hline $\mathbf{E}$ & $1 / 8,1 / 7,1 / 6$ & $1 / 6,1 / 5,1 / 4$ & $4,5,6$ & $1,1,1$ & $1 / 8,1 / 7,1 / 6$ & $1 / 6,1 / 5,1 / 4$ \\
\hline $\mathbf{T P}$ & $1 / 6,1 / 5,1 / 4$ & $1 / 4,1 / 3,1 / 2$ & $6,7,8$ & $6,7,8$ & $1,1,1$ & $1,1,1$ \\
\hline $\mathbf{P}$ & $1,1,1$ & $1,1,1$ & $6,7,8$ & $4,5,6$ & $1,1,1$ & $1,1,1$ \\
\hline
\end{tabular}

Tedarikçi C'ye ait performans kriterlerinin karşılaştırma matrislerinin belirlenen yönteme göre bulanık $\mathrm{AHP}^{\prime}$ de izlenecek Adım 2,3,4 ve 5 işlemlerine tabi tutulmuştur. Verilerin işlenmesi ile elde edilen değerlendirme sonuçları (ri,wi,Mi,Ni) Tablo 24`te ayrı ayrı verilmiş olup ana ve alt kriterlere ait performans ağırlık değerlerine (rank) ulaşılmıştır.

Tablo 24: TEDARİKÇI C'nın Bulanık Değerlendirme Sonuçları

\begin{tabular}{|c|c|c|c|c|c|c|c|c|c|}
\hline FIYAT & & $\mathrm{r} i$ & & & wi & & Mi & $\mathbf{N i}$ & Rank \\
\hline F1 & 1,000 & 1,119 & 1,260 & 0,204 & 0,257 & 0,333 & 0,265 & 0,259 & 2 \\
\hline F2 & 0,275 & 0,306 & 0,347 & 0,056 & 0,070 & 0,092 & 0,073 & 0,071 & 3 \\
\hline \multirow[t]{2}{*}{ F3 } & 2,520 & 2,924 & 3,302 & 0,514 & 0,673 & 0,872 & 0,686 & 0,670 & 1 \\
\hline & \multicolumn{6}{|c|}{$P(-1)[0,264 ; 0,230 ; 0,204]$} & & & \\
\hline KALITTE & \multicolumn{3}{|c|}{$\mathrm{r} i$} & \multicolumn{3}{|c|}{ wi } & Mi & $\mathbf{N i}$ & Rank \\
\hline K1 & 3,130 & 3,637 & 4,120 & 0,470 & 0,615 & 0,795 & 0,626 & 0,614 & 1 \\
\hline K2 & 0,243 & 0,275 & 0,319 & 0,036 & 0,046 & 0,062 & 0,048 & 0,047 & 3 \\
\hline K3 & 0,904 & 1,000 & 1,107 & 0,136 & 0,169 & 0,214 & 0,173 & 0,169 & 2 \\
\hline \multirow[t]{2}{*}{ K4 } & 0,904 & 1,000 & 1,107 & 0,136 & 0,169 & 0,214 & 0,173 & 0,169 & 2 \\
\hline & \multicolumn{6}{|c|}{$P(-1)[0,193 ; 0,169 ; 0,150]$} & & & \\
\hline TESLIMAT & \multicolumn{3}{|c|}{$\mathrm{r} i$} & \multicolumn{3}{|c|}{$\mathrm{w} i$} & Mi & $\mathbf{N i}$ & Rank \\
\hline T1 & 2,884 & 3,271 & 3,634 & 0,562 & 0,713 & 0,901 & 0,726 & 0,712 & 1 \\
\hline T2 & 0,275 & 0,306 & 0,347 & 0,054 & 0,067 & 0,086 & 0,069 & 0,068 & 3 \\
\hline \multirow[t]{2}{*}{ T3 } & 0,874 & 1,000 & 1,145 & 0,170 & 0,218 & 0,284 & 0,224 & 0,220 & 2 \\
\hline & \multicolumn{6}{|c|}{$P(-1)[0,248 ; 0,218 ; 0,195]$} & & & \\
\hline ESNEKLİK & & $\mathrm{r} i$ & & & $\mathrm{w} i$ & & Mi & $\mathrm{Ni}$ & Rank \\
\hline E1 & 0,639 & 0,669 & 0,707 & 0,104 & 0,120 & 0,141 & 0,122 & 0,120 & 2 \\
\hline E2 & 0,639 & 0,669 & 0,707 & 0,104 & 0,120 & 0,141 & 0,122 & 0,120 & 2 \\
\hline
\end{tabular}


Serbülent Kapıcı E İsmail Güçlü \& Yusuf Emre Karakaş

\begin{tabular}{|c|c|c|c|c|c|c|c|c|c|}
\hline E3 & 3,130 & 3,637 & 4,120 & 0,507 & 0,651 & 0,824 & 0,661 & 0,651 & 1 \\
\hline E4 & 0,595 & 0,615 & 0,639 & 0,096 & 0,110 & 0,128 & 0,111 & 0,110 & 3 \\
\hline \multicolumn{10}{|c|}{$P(-1)[0,200 ; 0,179 ; 0,162]$} \\
\hline T.PROFIL & & $\mathrm{ri}$ & & & $\mathrm{w} i$ & & Mi & $\mathbf{N i}$ & Rank \\
\hline TP1 & 1,260 & 1,424 & 1,619 & 0,156 & 0,191 & 0,243 & 0,197 & 0,195 & 3 \\
\hline TP2 & 0,397 & 0,460 & 0,550 & 0,049 & 0,062 & 0,083 & 0,064 & 0,064 & 5 \\
\hline TP3 & 1,906 & 2,172 & 2,221 & 0,236 & 0,291 & 0,333 & 0,287 & 0,284 & 1 \\
\hline TP4 & 1,698 & 1,809 & 1,906 & 0,211 & 0,242 & 0,286 & 0,246 & 0,244 & 2 \\
\hline TP5 & 1,122 & 1,270 & 1,414 & 0,139 & 0,170 & 0,212 & 0,174 & 0,172 & 4 \\
\hline TP6 & 0,275 & 0,306 & 0,347 & 0,034 & 0,041 & 0,052 & 0,042 & 0,042 & 6 \\
\hline \multicolumn{10}{|c|}{$P(-1)[0,150 ; 0,134 ; 0,124]$} \\
\hline PANDEMI & & $\mathrm{r} i$ & & & wi & & Mi & $\mathbf{N i}$ & Rank \\
\hline P1 & 1,000 & 1,000 & 1,000 & 0,333 & 0,333 & 0,333 & 0,333 & 0,333 & 1 \\
\hline $\mathbf{P 2}$ & 1,000 & 1,000 & 1,000 & 0,333 & 0,333 & 0,333 & 0,333 & 0,333 & 1 \\
\hline P3 & 1,000 & 1,000 & 1,000 & 0,333 & 0,333 & 0,333 & 0,333 & 0,333 & 1 \\
\hline \multicolumn{10}{|c|}{$\boldsymbol{P ( - 1 )}[0,333 ; 0,333 ; 0,333]$} \\
\hline ANA KRITTER & & $\mathrm{ri}$ & & & $\mathrm{w} i$ & & Mi & $\mathrm{Ni}$ & Rank \\
\hline FIYAT & 1,817 & 2,083 & 2,402 & 0,193 & 0,250 & 0,331 & 0,258 & 0,252 & 2 \\
\hline KALITE & 2,140 & 2,608 & 3,026 & 0,227 & 0,313 & 0,418 & 0,319 & 0,312 & 1 \\
\hline TESLIMAT & 0,185 & 0,209 & 0,240 & 0,020 & 0,025 & 0,033 & 0,026 & 0,025 & 6 \\
\hline ESNEKLİK & 0,347 & 0,400 & 0,467 & 0,037 & 0,048 & 0,064 & 0,050 & 0,049 & 5 \\
\hline TED.PROFILI I & 1,070 & 1,218 & 1,414 & 0,113 & 0,146 & 0,195 & 0,152 & 0,148 & 4 \\
\hline \multirow[t]{2}{*}{ PAND. YAK. } & 1,698 & 1,809 & 1,906 & 0,180 & 0,217 & 0,263 & 0,220 & 0,215 & 3 \\
\hline & \multicolumn{9}{|c|}{$P(-1)[0,138 ; 0,120 ; 0,106]$} \\
\hline
\end{tabular}

Hesaplamalar sonucu Tablo 24'te Tedarikçi C'nin ödeme yaklaşımı(F3), ürün kalitesi (K1), doğru ürün ve miktar teslimat (T1), ürün-zaman-miktar karşılama (E3), kapasite-ürün çeşitliliği (TP3), pandemi yaklaşımında ise hepsi eşit olarak performans alt kriterlerinin yüksek olduğu gözlemlenirken ana kriterlerinin karşılaştırmasında ise öncelikli olarak kalite performansının ilk sırada fiyatın ise ikinci sırada olduğu belirlenmiştir.

\section{Sonuç}

Tedarikçi değerlendirme ve seçim süreci, işletmelerin tedarik zincirinin etkin bir şekilde yönetilebilmesi için birçok kriterin göz önünde bulundurulmasını gerektiren hayati öneme haiz bir süreçtir. İşletmeler çalışacakları tedarikçileri bu kriterlere göre çok iyi analiz etmeli ve ona göre aradıkları kriterlere uygun tedarikçilerle iş birliğine gitmelidirler. Firmalar için doğru tedarikçiler ile iş ortaklıkları kurularak çalışmak işletme performansını direkt etkileyen bir karardır. 
Ana performans kriterleri açısından tedarikçilerin birbirleriyle olan performanslarının karşılaştırılarak sıralandırılması amacına yönelik olarak bulanık ikili karşılaştırma matrisi Tablo $25^{\prime}$ de verilmiştir. Bu tablo yardımıyla, ayrıntılı olarak açıklanan bulanık AHP analizi yöntemi kullanılıp ağırlık vektörleri elde edilmiş ve performans ana kriterlere ait birleşik önem ağırlıklarına ulaşılmıştır.

Tablo 25: Ana Kriterlerin Bulanık Değerlendirme Sonuçları

\begin{tabular}{|c|c|c|c|c|}
\hline KRİTERLER & TEDARİKÇİLER & TD A & TD B & TD C \\
\hline \multirow{3}{*}{ FIYAT } & TD A & $1,1,1$ & $6,7,8$ & $6,7,8$ \\
\hline & TD B & $1 / 8,1 / 7,1 / 6$ & $1,1,1$ & $4,5,6$ \\
\hline & TD C & $1 / 8,1 / 7,1 / 6$ & $1 / 6,1 / 5,1 / 4$ & $1,1,1$ \\
\hline \multirow{3}{*}{ KALİTE } & TD A & $1,1,1$ & $1,8 /, 1 / 7,1 / 6$ & $1 / 8,1 / 7,1 / 6$ \\
\hline & TD B & $6,7,8$ & $1,1,1$ & $1 / 8,1 / 7,1 / 6$ \\
\hline & TD C & $6,7,8$ & $6,7,8$ & $1,1,1$ \\
\hline \multirow{3}{*}{ TESLIMMAT } & TD A & $1,1,1$ & $2,3,4$ & $8,9,9$ \\
\hline & TD B & $1 / 4,1 / 3,1 / 2$ & $1,1,1$ & $6,7,8$ \\
\hline & TD C & $1 / 9,1 / 9,1 / 9$ & $1 / 8,1 / 7,1 / 6$ & $1,1,1$ \\
\hline \multirow{3}{*}{ ESNEKLİK } & TD A & $1,1,1$ & $1,8 /, 1 / 7,1 / 6$ & $2,3,4$ \\
\hline & TD B & $6,7,8$ & $1,1,1$ & $6,7,8$ \\
\hline & TD C & $1 / 4,1 / 3,1 / 2$ & $1 / 8,1 / 7,1 / 6$ & $1,1,1$ \\
\hline \multirow{3}{*}{ TED. PROFILİ } & TD A & $1,1,1$ & $1 / 6,1 / 5,1 / 4$ & $4,5,6$ \\
\hline & TD B & $4,5,6$ & $1,1,1$ & $6,7,8$ \\
\hline & TD C & $1 / 6,1 / 5,1 / 4$ & $1 / 8,1 / 7,1 / 6$ & $1,1,1$ \\
\hline \multirow{3}{*}{$\begin{array}{l}\text { PANDEMI } \\
\text { YAKLAŞIMI }\end{array}$} & TD A & $1,1,1$ & $1,1,1$ & $1,1,1$ \\
\hline & TD B & $1,1,1$ & $1,1,1$ & $1,1,1$ \\
\hline & TD C & $1,1,1$ & $1,1,1$ & $1,1,1$ \\
\hline
\end{tabular}

Tedarikçilere ait performans kriterlerinin karşılaştırma matrislerinin belirlenen yönteme göre bulanık $\mathrm{AHP}^{\prime}$ de izlenecek Adım 2,3,4 ve 5 işlemlerine tabi tutulmuştur. Verilerin işlenmesi ile elde edilen değerlendirme sonuçları (ri,wi,Mi,Ni) Tablo 26' da ayrı ayrı verilmiş olup ana kriterlere ait performans ağırlık değerlerine (Rank) ulaşılmıştır. 
Tablo 26: Ana Kriterlere Göre Her Tedarikçi İçin Toplu Değerlendirme Sonuçları

\begin{tabular}{|c|c|c|c|c|c|c|c|c|c|}
\hline \multirow{5}{*}{ 究 } & & & $\mathrm{ri}$ & & & $W i$ & & Mi & $\mathrm{Ni}$ \\
\hline & TD A & 3,302 & 3,659 & 4,000 & 0,617 & 0,754 & 0,916 & 0,762 & 0,752 \\
\hline & TD B & 0,794 & 0,894 & 1,000 & 0,148 & 0,184 & 0,229 & 0,187 & 0,185 \\
\hline & TD C & 0,275 & 0,306 & 0,347 & 0,051 & 0,063 & 0,079 & 0,065 & 0,064 \\
\hline & & Total & $(4,371 ;$ & $859 ; 5,3$ & ) $P(-1)$ & 0,$229 ; 0$ & $06 ; 0,187$ & & \\
\hline \multirow{4}{*}{ 荘 } & & & $\mathrm{ri}$ & & & $W i$ & & Mi & $\mathrm{Ni}$ \\
\hline & TD A & 0,250 & 0,273 & 0,303 & 0,046 & 0,055 & 0,068 & 0,057 & 0,056 \\
\hline & TD B & 0,909 & 1,000 & 1,101 & 0,168 & 0,203 & 0,247 & 0,206 & 0,203 \\
\hline & TD C & 3,302 & 3,659 & 4,000 & 0,611 & 0,743 & 0,896 & 0,750 & 0,741 \\
\hline
\end{tabular}

Total $(4,460 ; 4,933 ; 5,403) \mathbf{P ( - 1 )}[0,224 ; 0,203 ; 0,185]$

\begin{tabular}{|c|c|c|c|c|c|c|c|c|c|}
\hline \multirow{5}{*}{ 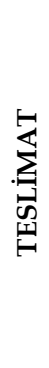 } & & \multicolumn{3}{|c|}{$\mathrm{ri}$} & \multicolumn{3}{|c|}{ Wi } & \multirow{2}{*}{$\frac{\mathbf{M i}}{0,663}$} & \multirow{2}{*}{$\frac{\mathrm{Ni}}{0,649}$} \\
\hline & TD A & 2,621 & 3,000 & 3,302 & 0,508 & 0,654 & 0,825 & & \\
\hline & TD B & 1,145 & 1,326 & 1,587 & 0,222 & 0,289 & 0,397 & 0,303 & 0,296 \\
\hline & TD C & 0,240 & 0,251 & 0,265 & 0,047 & 0,055 & 0,066 & 0,056 & 0,055 \\
\hline & \multicolumn{9}{|c|}{ Total $(4,006 ; 4,578 ; 5,154) \quad P(-1)[0,250 ; 0,218 ; 0,194]$} \\
\hline \multirow{4}{*}{ 光 } & & & $\mathrm{ri}$ & & & Wi & & Mi & $\mathrm{Ni}$ \\
\hline & TD A & 0,630 & 0,754 & 0,874 & 0,118 & 0,158 & 0,205 & 0,160 & 0,158 \\
\hline & TD B & 3,302 & 3,659 & 4,000 & 0,621 & 0,765 & 0,940 & 0,775 & 0,764 \\
\hline & TD C & 0,315 & 0,362 & 0,437 & 0,059 & 0,076 & 0,103 & 0,079 & 0,078 \\
\hline
\end{tabular}

Total $(4,247 ; 4,776 ; 5,310) \mathbf{P ( - 1 )}[0,248 ; 0,218 ; 0,195]$

\begin{tabular}{|c|c|c|c|c|c|c|c|c|c|}
\hline \multirow{5}{*}{ 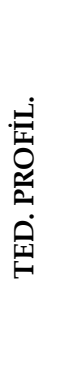 } & & \multicolumn{3}{|c|}{ ri } & \multicolumn{3}{|c|}{$W i$} & \multirow{2}{*}{$\frac{\text { Mi }}{0,224}$} & \multirow{2}{*}{$\frac{\mathrm{Ni}}{0,220}$} \\
\hline & TD A & 0,874 & 1,000 & 1,145 & 0,170 & 0,218 & 0,284 & & \\
\hline & TD B & 2,884 & 3,271 & 3,634 & 0,562 & 0,713 & 0,901 & 0,726 & 0,712 \\
\hline & TD C & 0,275 & 0,306 & 0,347 & 0,054 & 0,067 & 0,086 & 0,069 & 0,068 \\
\hline & \multicolumn{9}{|c|}{ Total $(4,033 ; 4,577 ; 5,126) \quad P(-1)[0,248 ; 0,218 ; 0,195]$} \\
\hline \multirow{5}{*}{ 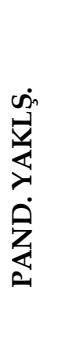 } & & \multicolumn{3}{|c|}{$\mathrm{ri}$} & \multicolumn{3}{|c|}{$W i$} & Mi & $\mathbf{N i}$ \\
\hline & TD A & 0,874 & 1,000 & 1,145 & 0,170 & 0,218 & 0,284 & 0,224 & 0,220 \\
\hline & TD B & 2,884 & 3,271 & 3,634 & 0,562 & 0,713 & 0,901 & 0,726 & 0,712 \\
\hline & TD C & 0,275 & 0,306 & 0,347 & 0,054 & 0,067 & 0,086 & 0,069 & 0,068 \\
\hline & \multicolumn{9}{|c|}{ Total $(3,000 ; 3,000 ; 3,000) \quad P(-1)[0,333 ; 0,333 ; 0,333]$} \\
\hline
\end{tabular}

Tablo $26^{\prime}$ da tedarikçilere ait ana kriter performans değerleri ayrı ayrı hesaplanmış olup elde edilen performans ağırlık değerleri bütünleşik olarak Tablo $27^{\prime}$ de verilmiştir. 
Tablo 27: Tedarikçilerin Performanslarının Toplu Değerlendirme Sonuçları

\begin{tabular}{lcccc}
\hline & KRITERLER & & \multicolumn{3}{c}{ Ilgili Kriterlere Göre Alternatif } \\
Ağırlıları
\end{tabular}

Hesaplamalar sonucu Tablo $27^{\prime}$ de elde edilen $\mathrm{Ni}$ değerleriyle tedarikçilerin birbirleriyle karşılaştırılması sonucunda fiyat performansında Tedarikçi A, kalite performansında Tedarikçi C, teslimat performansında Tedarikçi A, esneklik performansında Tedarikçi B, tedarikçi profil performansında Tedarikçi $B$ ve pandemi yaklaşımı performansının ise eşit olduğu gözlemlenmiştir.

Tablo 28: Tedarikçilerin Performanslarının Yüzdelik Sonuçları

\begin{tabular}{lcc}
\hline TEDARIKÇİLER & $\%$ & DERECE \\
\hline TEDARÍKÇİ A & $\% 40,00$ & 1 \\
\hline TEDARÍKÇİ B & $\% 32,30$ & 2 \\
\hline TEDARÍKÇİ C & $\% 27,70$ & 3 \\
\hline
\end{tabular}

Tablo 28'de Tedarikçi A'nın \%40, Tedarikçi B'nin \%32,3 ve Tedarikçi C'nin ise \% 27,70 performans gösterdiği gözlemlenmiştir.

Söz konusu çalışma konaklama işletmeleri için yapılmıştır. Bu yöntem uygulanarak farklı sektörlerde, farklı değerlendirme kriterleri kullanılarak yapılabilir. Ayrıca bu yöntem, yeni tedarikçilerin seçim tercihlerinde, karar vericiler tarafından uygulanabilir. COVID-19 pandemi süreci sonrası benzer çalışmalar yapılarak tedarikçi performans değerlendirmesi karşılaştırması yapılabilir.

\section{Hakem Değerlendirmesi / Peer-review:}

Dış bağımsız

Externally peer-reviewed

\section{Çıkar Çatışması / Conflict of interests:}

Yazar(lar) çıkar çatışması bildirmemiştir.

The author(s) has (have) no conflict of interest to declare. 


\section{Finansal Destek / Grant Support:}

Yazar(lar) bu çalışma için finansal destek almadığını beyan etmiştir.

The author(s) declared that this study has received no financial support.

\section{Etik Kurul Onayı / Ethics Committee Approval:}

Bu çalışma için etik kurul onayı, Sinop Üniversitesi, İnsan Araştırmaları Etik Kurulu/Komitesinden 10/04/2021 tarihli 2021/60 sayılı karar ile alınmıştır.

Ethics committee approval was received for this study from Sinop University, Insan Araştırmalarn Ethics Committee on 10/04./2021 and 2021/60 document number.

\section{Yazar Katkıları / Author Contributions:}

Fikir/Kavram/Tasarım - Idea/Concept/ Design: Y.E.K., S.K., İ.G. Veri Toplama ve/veya İşleme - Data Collection and/or Processing: Y.E.K. Analiz ve/veya Yorum - Analysis and/or Interpretation: İ.G. Kaynak Taramas1 - Literature Review: S.K., Y.E.K. Makalenin Yazımı - Writing the Article: Y.E.K., S.K., İ.G. Eleştirel İnceleme - Critical Review: S.K., İ.G. Onay - Approval: S.K., Y.E.K., İ.G.

\section{Kaynakça / References}

Abdel-Kader, M.G. \& Dugdale, D. (2001) Evaluating investments in advanced manufacturing technology: A fuzzy set theory approach, British Accounting Review, 33(1), 455-489.

Acar, D. ve Ateş, B. A. (2011). Tedarik Zinciri Temel Faaliyetlerinde Dış Kaynak Kullanımı: TekstilKonfeksiyon Sektörü İşletmelerinde Bir Araştırma. Mali Çözüm, 21 (105), 17-46.

Akal, Z. (2005). İşletmelerde Performans Ölçüm ve Denetimi: Çok Yönlü Performans Göstergeleri (6.Baskı). Ankara: Milli Prodüktivite Merkezi Yayınları.

Akdemir, A. (2009). İşletmeciliğin Temel Bilgileri. Bursa: Ekin Yayınları.

Akman, G. ve Alkan, A. (2006). Tedarik Zinciri Yönetiminde Bulanık AHP Yöntemi Kullanılarak Tedarikçilerin Performansının Ölçülmesi: Otomotiv Yan Sanayiinde Bir Uygulama. İstanbul Ticaret Üniversitesi Fen Bilimleri Dergisi, 5 (9), 23-46.

Al-Aomar, R. ve Hussain, M. (2017). An assessment of green practices in a hotel supply chain: A study of UAE hotels. Journal of Hospitality and Tourism Management, 32, 71-81.

Bahar, O. ve Çelik İlal, N. (2020). Coronavirüsün (COVID-19) Turizm Sektörü Üzerindeki Ekonomik Etkileri. International Journal of Social Sciences and Education Research, 6(1), 125-139.

Batman, O., Bilgiçli, İ. ve Yıldırgan, R. (2020). Otel Çalışanı ve Misafirinin COVID-19 Pandemi Kurallarına Uyumu: Antalya ve Muğla Karşılaştırması, Sosyal, Beşeri ve İdari Bilimler Dergisi, 3(12), 935-955.

Buckley, J.J. (1985). Fuzzy Hierarchical Analysis, Fuzzy Sets Systems, 17(1), 233-247.

Chang, D.Y. (1996). Applications of the extent analysis method of fuzzy AHP. European Journal of Operational Research, 95(3), 649-655.

Faris, C. W, Robinson, P. J., Wind, Y. (1967). Industrial Buying and Creative Marketing. USA: Allyn and Bacon Publisher.

Ghodsypour, S.H. ve O'Brien,C. (1998). A Decision Support System for Supplier Selection Using An Integrated Analytic Hierarchy Process and Linear Programming, Int. J. Production Economics, 5657, 199-212.

Göktürk, İ. F., Eryılmaz, A. Y. ve Yuluğkural, Y. (2011). Bir İşletmenin Tedarikçi Değerlendirme ve Seçim Probleminin Çözümünde AAS ve VIKOR Yöntemlerinin Kullanılması. Dumlupınar Üniversitesi Fen Bilimler Enstitüsü Dergisi, (025), 61-74. 
Habib, M. (2011). Supply Chain Management-Theory and Evolution. Bangladesh: American International University.

Kazançoğlu, Y. ve Özturkoğlu, Y. (2018). Integrated Framework of Disassembly Line Balancing with Green and Business Objectives Using a Mixed MCDM. Journal of Cleaner Production, (191), 179-191.

Kıvılcım, B. (2020). COVID-19 (Yeni Koronavirüs) Salgınının Turizm Sektörüne Muhtemel Etkileri. Uluslararası Batı Karadeniz Sosyal ve Beşeri Bilimler Dergisi, 4(1): 17-27.

Kozak, N., Akoğlan Kozak, M. ve Kozak M. (2014). Genel Turizm İlkeler-Kavramlar. Ankara: Detay Yayıncilik.

Lee, C.C. ve Chang, C.P. (2008). Tourism Development and Economic Growth: A Closer Look at Panels. Tourism Management, 29, 180-192.

Liou, T.S. ve Wang, M.J. (1992). Ranking fuzzy numbers with integral value, Fuzzy Sets and Systems, 50(3), 247- 255.

Lu, M., ve De Bock, J. (2016). Sustainable Logistics and Supply Chains. Switzerland: Springer.

Manap Davras, G. ve Karaatlı, M. (2014). Otel işletmelerinde tedarikçi seçimi sürecinde AHP ve BAHP yöntemlerinin uygulanması. Hacettepe Üniversitesi İktisadi ve İdari Bilimler Fakültesi Dergisi, 32 (1), 87-112.

Nebol, E. (2016). Tedarik Zinciri ve Lojistik Yönetimi (1.Basım b.). Ankara: Nobel Akademik Yayıncılık.

Sadraoui T. ve Mchirgui N. (2014). Supply Chain Management Optimization within Information System Development. International Journal of Econometrics and Financial Management, 2(2), 59-71.

Önder, E. ve Kabaday1, N. (2015). Supplier Selection in Hospitality Industry Using ANP. International Journal of Academic Research in Business and Social Sciences, 5 (1).

Önüt, S., Kara, S. S. ve Işik, E. (2009). Long term Supplier Selection Using A Combined Fuzzy MCDM approach: A case study for a telecommunication company. Expert Systems with Applications, 36(2 ), 3887-3895.

Ross, D. F. (2000). Creating Market - Winning Strategies Through Supply Chain Partnerships. Competing Through Supply Chain Management, 7-9.

Sarıŏlan, M. (2011). Konaklama İşletmelerinde Tedarik Zinciri Yönetimi Kapsamında Tedarikçi Seçim Kriterleri Üzerine Görgül Bir Araştırma. Balıkesir Üniversitesi Sosyal Bilimler Enstitüsü Dergisi, 14 (25), 239-253.

Tellioğlu, S. ve Etlioğlu, M. (2019). Herşey Dahil Otellerdeki Satınalma Yöneticilerinin Satınalma Davranışlarını ve Kararlarını Etkileyen Faktörler. Sosyal Bilimler Elektronik Dergisi, 3 (4), 132-149.

Țigu, G. ve Călărețu, B. (2013). Supply Chain Management Performance in Tourism. Continental Hotels Chain Case. The AMFITEATRU ECONOMIC journal, Academy of Economic Studies - Bucharest, Romania, vol. 15(33), 103-115.

Tunçer, P. (2013). Örgütlerde Performans Değerlendirme ve Motivaston. Sayıştay Dergisi, 88, 87-108.

Ünal, Z., Güven, S. ve İpekçi Çetin, E. (2019). Otel işletmelerinin tedarikçi seçiminde bulanık AHP ile ağırlıklandırılmış hedef programlama uygulaması. Hitit Üniversitesi Sosyal Bilimler Enstitüsü Dergisi, 12(1), 188-204.

Xia, W. ve Wu, Z. (2007). Supplier selection with multiple criteria in volume discount environments. Omega, 35(5), 494-504.

Zadeh, L.A. (1965). Fuzzy Sets, Journal Information and Control, 8(3), 199-249.

Zheng, C. ve Zhang, J. (2020). The Impact of COVID-19 On The Efficiency Of Microfinance Institutions. International Review of Economics \& Finance, 71, 407-423.

\section{İnternet Kaynakları}

https://www.euro.who.int/en/health-topics/health-emergencies/coronavirus-covid-19/novelcoronavirus-2019-ncov

https://covid19.saglik.gov.tr/Eklenti/39551/0/covid19rehberigenelbilgilerepidemiyolojivetanipdf.p $\underline{\mathrm{df}}$ 